\title{
Association of Low Leptin with Poor 3-Month Prognosis in Ischemic Stroke Patients with Type 2 Diabetes
}

This article was published in the following Dove Press journal: Clinical Interventions in Aging

\author{
Yi Zou' \\ Ling $\mathrm{Hu}{ }^{\prime}$ \\ Wenjun Zou ${ }^{2}$ \\ Honglin $\mathrm{Li}^{3}$ \\ 'Department of Endocrinology, The \\ Third Affiliated Hospital of Nanchang \\ University, Nanchang, People's Republic \\ of China; ${ }^{2}$ General Surgery, Nanchang \\ Third Hospital, Nanchang, People's \\ Republic of China; ${ }^{3}$ Department of \\ Biochemistry, Medical College of \\ Georgia, Augusta, GA, USA
}

Background: Leptin, an adipokine, has effects on the cardiovascular system with both protective and harmful role. This study aimed to assess the relationship between leptin and 3-month prognosis in ischemic stroke patients with type 2 diabetes.

Patients and Methods: As a prospective single-center observational study, we collected consecutive first-ever acute ischemia stroke with type 2 diabetes mellitus from February 2019 to February 2020. Serum samples were obtained at admission, and leptin serum levels were tested by the ELISA method. Logistic regression models were used to assess leptin's prognostic value to predict the functional outcome and mortality within three months.

Results: Finally, two hundred and eleven patients were included, and the mean leptin serum level was 16.8 (SD. 6.9) $\mathrm{ng} / \mathrm{mL}$. At admission, $53.6 \%$ of those included patients $(\mathrm{N}=113$ ) were defined as severe stroke (NIH Stroke Scale [NIHSS] $>5$ ). In multivariable models adjusted for other factors, leptin levels $<11.6 \mathrm{ng} / \mathrm{mL}$ (lowest quartile, Q1) related to severe stroke and the risk increased $175 \%$ (odds ratios $[\mathrm{OR}]=2.75 ; 95 \%$ confidence interval $[\mathrm{CI}]$ $=2.13-3.38 ; \mathrm{P}=0.002$ ). Serum leptin levels on admission in patients with poor outcomes and nonsurvivors were significantly reduced $(\mathrm{P}<0.001$ and $\mathrm{P}<0.001)$. Leptin levels $<11.6 \mathrm{ng} / \mathrm{mL}$ (lowest quartile, Q1) related to a higher risk of poor functional impairment $(\mathrm{OR}=5.13 ; 95 \%$ $\mathrm{CI}=3.25-6.86 ; \mathrm{P}<0.001)$ and mortality $(\mathrm{OR}=3.19 ; 95 \% \mathrm{CI}=2.03-4.25 ; \mathrm{P}<0.001)$.

Conclusion: The data shows that leptin serum level is a useful prognostic biomarker in ischemic stroke patients with type 2 diabetes, and this relationship is negative.

Keywords: leptin, adipokine, ischemic stroke, type 2 diabetes, prognosis

\section{Background}

Leptin was identified in 1994 as an adipocyte-derived signaling factor, which, after interaction with its receptors, played an intricate role in body weight and energy expenditure. ${ }^{1}$ Furthermore, leptin plays a role in the regulation of neuroendocrine and immune function. ${ }^{2}$ Loffreda et $\mathrm{al}^{3}$ showed that leptin played a role in the upregulation of inflammatory immune responses, contributing to several significant obesity complications.

Plasma leptin levels correlate strongly with diabetes ${ }^{4}$ and metabolic syndrome. ${ }^{5}$ Leptin receptors could express in the cardiovascular system, ${ }^{6}$ and some studies found that hyperleptinemia had effects on obesity-associated cardiovascular diseases and atherosclerosis. ${ }^{7}$ Knudson et $\mathrm{al}^{8}$ showed that hyperleptinemia could produce significant coronary endothelial dysfunction. In addition to its role in anti-obesity, leptin
Correspondence: Ling Hu

Department of Endocrinology, The Third Affiliated Hospital of Nanchang

University, No. 128 Xiangshan North

Road, Nanchang 330000, Jiangxi Province,

People's Republic of China

Tel +86 79l-88862350

Email hul@medmail.com.cn 
also presented antidiabetic actions. ${ }^{9}$ In patients with type 2 diabetes, Reilly et $\mathrm{al}^{10}$ reported that leptin plasma levels were related to coronary artery calcification.

The leptin role in predicting carotid intima-media thickness, carotid plaque instability, and cerebrovascular disease was proposed. ${ }^{11,12}$ However, the association between leptin and stroke was not confirmed in the other two studies. ${ }^{13,14}$ Furthermore, one study showed that serum level of leptin was related to lesion size and stroke severity, ${ }^{15}$ while another study reported that serum leptin level at discharge could predict post-stroke depression development during the next month. ${ }^{16}$ A review suggested that leptin's blood level was a useful prognostic biomarker for inflammation and atherosclerosis in stroke. ${ }^{17}$ However, the relationship between leptin and functional impairment in ischemic stroke with type 2 diabetes is still not well understood. Thus, this study aimed to assess the relationship between leptin and 3-month prognosis in ischemic stroke patients with type 2 diabetes.

\section{Patients and Methods}

As a prospective single-center observational study, we collected consecutive first-ever acute ischemia stroke (AIS) with type 2 diabetes mellitus from February 2019 to February 2020. Those patients were from the Department of Emergency of our hospital and presented with symptom onset within 48 hours. AIS and diabetes were defined according to the World Health Organization criteria. ${ }^{18,19}$ Patients with tumors, metabolic syndrome, intracerebral hemorrhage, liver, renal insufficiency, systemic infections, and autoimmune diseases were excluded.

One hundred age and sex-matched healthy volunteers from our hospital's physical examination center were assigned to the healthy control group. The mean age was 67.5 years, and $42.0 \%$ were women. The Ethics Committee of the Nanchang University Third Hospital reviewed and approved the trial protocol according to the Declaration of Helsinki (1964). Written informed consent was obtained from patients before entering the study. We confirmed that any data intended for sharing would be de-identified.

MRI confirmed the clinical diagnoses of stroke within 24 hours after admission, and Dr. Li determined diffusionweighted imaging (DWI) lesion volumes according to the formula $0.5 \times \mathrm{a} \times \mathrm{b} \times \mathrm{c}$ (specific information could be found in the literature).$^{20}$ Ischemic strokes were classified according to the original Trial of Org 10,172 in Acute Stroke Treatment (TOAST) criteria. ${ }^{21}$ National Institutes of Health Stroke Scale (NIHSS) was used to assess stroke's clinical severity on admission. $^{22}$ A severe stroke was defined as an NIHSS of more than 5 .

Within 24 hours after admission, some information was recorded: vital signs; medication before stroke (hypertension, hypercholesterolemia, atrial fibrillation, cardiovascular diseases, peripheral vascular disease, and transient ischemic attack); IV thrombolysis and mechanical thrombectomy as acute stroke treatment; common factors (ie, age; sex; body index mass [BMI], smoking history; duration of diabetes; insulin and/or hypoglycemic agents as diabetes treatment). Fasting blood samples from all participants were collected within the first $24 \mathrm{~h}$ after admission, and serum samples were separated and used to test leptin levels by a commercially available quantitative enzymelinked immunosorbent assay (ELISA) kit (Abcam, China). In this study, the detection range was from $4.0 \mathrm{ng} / \mathrm{mL}$ to $400.0 \mathrm{ng} / \mathrm{mL}$, and the intra and inter-assay coefficient of variation $[\mathrm{CV}]$ was $5.2-8.3 \%$ and $5.8 \%-9.2 \%$, respectively.

We conducted a 3-month follow-up by a structured telephone interview. The functional impairment was assessed, and a poor functional impairment was defined as a modified Rankin scale (mRS) score of 3 to 6 points, while a good outcome was described as an mRS score of 0 to 2 points. ${ }^{23}$ Besides, death events and the causes of death during follow-up were recorded.

\section{Statistical Analysis}

Data results were recorded as categorical variables (number [\%]) and continuous variables (means [Standard deviation, $\mathrm{SD}]$ ). Results between different groups were compared by the chi-square and unpaired $T$-test when appropriate.

Associations between leptin serum level and either severe stroke, poor functional impairment, or mortality at follow-up were analyzed using logistic regression models. The results were presented as odds ratios (OR) and 95\% confidence intervals (CI). Serum leptin levels were categorized into quartiles, and the lowest quartile (Q1) was compared to the other three quartiles (Q2-Q4, as the reference). In multivariate models, we included all variables with a p-value $<0.05$ in unadjusted models.

Lastly, the optimal threshold of serum level of leptin in diagnosing either high clinical severity reduced functional impairment, or mortality was assessed by the receiver operating characteristic (ROC) curves to obtain the area under the curve (AUC) and 95\% CI. Significance was set at $\mathrm{P}<0.05$, and all statistical analysis was assessed by the SPSS22.0 software (SPSS Inc, Chicago, USA). 


\section{Data Sharing}

Please contact the corresponding author for all data requests.

\section{Results}

As shown in Figure 1, 408 ischemia stroke patients with diabetes were screened, and finally, 211 patients were included and analyzed. However, the baseline characteristics [age $(\mathrm{P}=0.11)$, gender $(\mathrm{P}=0.51)$, NIHSS $(\mathrm{P}=0.17)$, and BMI $(\mathrm{P}=0.63)]$ in those included patients were similar to the screened patients. Those patients' mean age was 67.3 (SD. 11.3) years, and $57.3 \%$ were male. The leptin serum level was obtained with a mean value of 16.8 (SD. 6.9) $\mathrm{ng} /$ $\mathrm{mL}$, and the median value was $16.3 \mathrm{ng} / \mathrm{mL}$ (IQR, 11.621.3). The mean serum level of leptin in AIS was significantly lower than in those control cases (16.8[SD:6.8] vs 18.5 [7.2] ng/mL; $\mathrm{P}<0.001)$. The serum levels of leptin were not related to the time from stroke symptom onset to blood collected $(\mathrm{P}=0.38)$. The baseline characteristics of those 211 included cases are presented in Table 1.
At admission, $53.6 \%$ of those included patients $(\mathrm{N}=113)$ were defined as severe stroke. The mean leptin serum level was lower in those patients than in those patients with minor clinical severity $(15.7[\mathrm{SD}, 7.0] \mathrm{ng} / \mathrm{mL}$ vs $18.0[6.5]$ $\mathrm{ng} / \mathrm{mL}, \mathrm{P}=0.014$ ), Figure 2A. In multivariable models adjusted for other factors, leptin levels $<11.6 \mathrm{ng} / \mathrm{mL}$ (lowest quartile, Q1) related to severe stroke and the risk increased $175 \%$ (odds ratios $[\mathrm{OR}]=2.75 ; 95 \%$ confidence interval $[\mathrm{CI}]=2.13-3.38 ; \mathrm{P}=0.002$ ). As shown in Figure 2B, the cutoff value of serum leptin in diagnosing severe stroke was estimated to be $12.0 \mathrm{ng} / \mathrm{mL}$ with the AUC (95\% CI) of 0.61 (0.53-0.68), which showed that the sensitivity and specificity were $86.7 \%$ and $38.9 \%$, respectively.

At 3-month, 133 patients $(63.0 \%)$ had good functional impairment whereas 78 patients $(37.0 \%)$ had unfavorable functional impairment. The mean leptin serum level was lower in the latter group than that observed in patients with good functional impairment (12.6[SD. 5.1]ng/mL vs 19.3 [6.6] $\mathrm{ng} / \mathrm{mL}, \mathrm{P}<0.001$ ) (Figure $3 \mathrm{~A}$ ). The data showed that 41 out of 54 patients $(75.9 \%)$ with low serum leptin

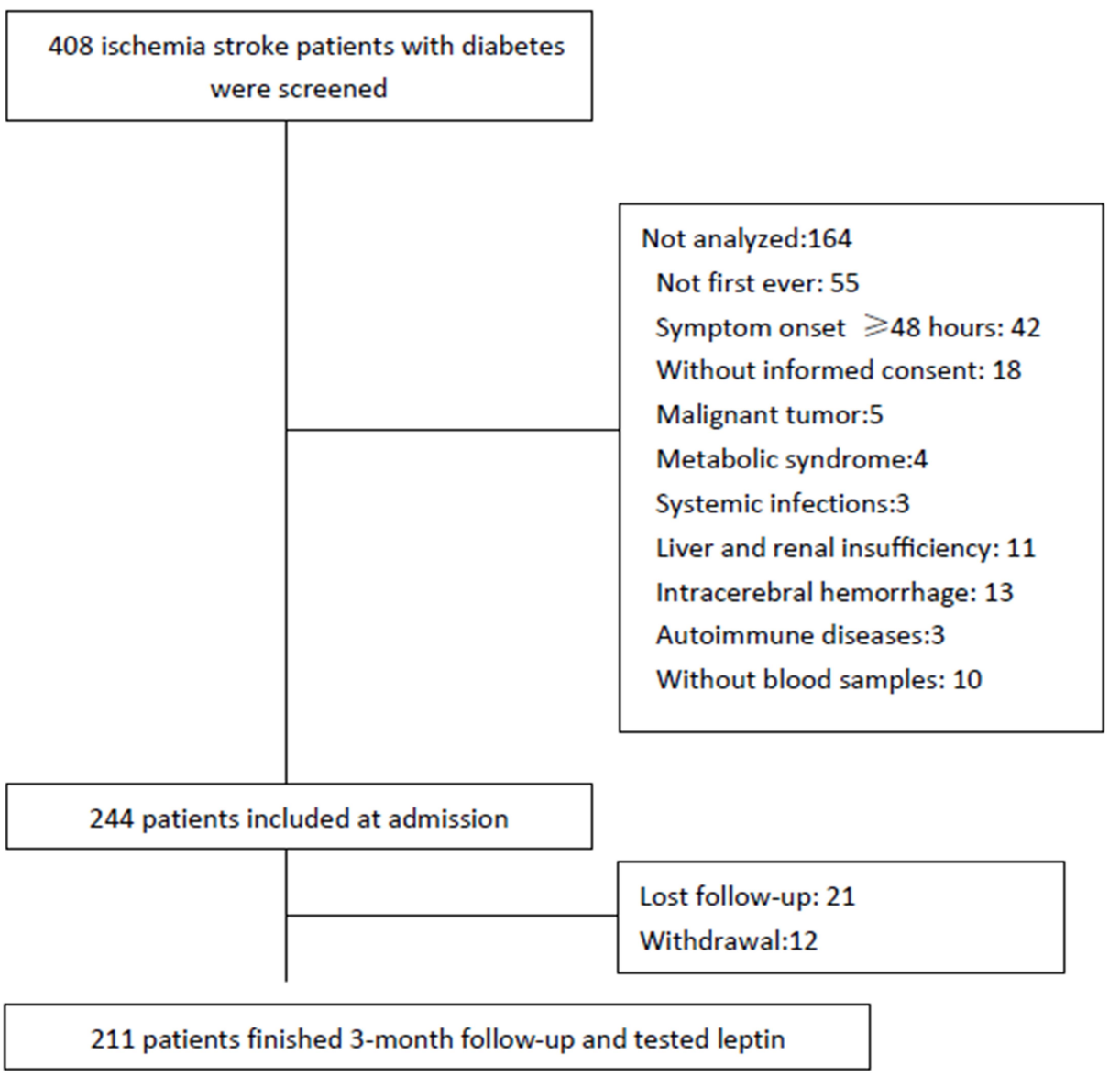

Figure I Study profile/flow sheet of the study. 
Table I Baseline Characteristics of Stroke Patients with Diabetes ${ }^{\ddagger}$

\begin{tabular}{|c|c|c|c|c|}
\hline Characteristics & Total & Low Leptin & Normal Leptin & $\mathbf{P}^{\ddagger}$ \\
\hline $\mathrm{N}$ & 211 & 54 & 157 & - \\
\hline Age, years mean $( \pm S D)$ & $67.3(11.3)$ & $66.9(11.3)$ & $67.4(11.4)$ & 0.86 \\
\hline$<60$ & $58(27.5)$ & $16(29.6)$ & $42(26.8)$ & - \\
\hline $60-74$ & $82(38.9)$ & $21(38.9)$ & $61(38.9)$ & - \\
\hline$\geq 75$ & 7I (33.6) & $17(3 \mid .5)$ & $54(34.4)$ & - \\
\hline Male gender & $121(57.3)$ & $36(66.7)$ & $85(54.1)$ & 0.38 \\
\hline BMI, kg/m2 mean $( \pm S D)$ & $24.4(3.7)$ & $22.8(2.6)$ & $24.9(3.7)$ & 0.43 \\
\hline Duration of diabetes, years mean $( \pm S D)$ & II.5 (2.8) & $13.8(3.0)$ & II.I (2.7) & $<0.001$ \\
\hline Intensive glucose treatment $^{\dagger}$ & $75(35.5)$ & $23(42.6)$ & $52(33.1)$ & 0.209 \\
\hline \multicolumn{5}{|l|}{ Vascular risk factors } \\
\hline Hypertension & $127(60.2)$ & $35(64.8)$ & $92(58.6)$ & 0.421 \\
\hline Hypercholesterolemia & $62(29.4)$ & $18(33.3)$ & $44(28.0)$ & 0.460 \\
\hline Atrial fibrillation & $31(14.7)$ & $8(14.8)$ & $23(14.6)$ & 0.976 \\
\hline CVD & $45(21.3)$ & $15(27.8)$ & $30(19.1)$ & 0.180 \\
\hline TIA & $22(10.4)$ & $10(18.5)$ & $12(7.6)$ & 0.024 \\
\hline Smoking & $41(19.4)$ & $12(22.2)$ & $29(18.5)$ & 0.550 \\
\hline Peripheral vascular disease & $9(4.3)$ & $2(3.7)$ & $7(4.5)$ & 0.225 \\
\hline Stroke etiology & & & & 0.104 \\
\hline Small-vessel occlusive & $42(19.9)$ & $12(22.2)$ & $30(19.1)$ & - \\
\hline Large-vessel occlusive & $44(20.9)$ & II (20.3) & $33(21.0)$ & - \\
\hline Cardioembolic & $73(34.6)$ & $20(37.0)$ & $53(33.8)$ & - \\
\hline Other & $21(10.0)$ & $8(14.8)$ & $13(12.1)$ & - \\
\hline Unknown & $31(14.7)$ & $3(5.6)$ & $28(17.8)$ & - \\
\hline \multicolumn{5}{|l|}{ Acute treatment } \\
\hline IV thrombolysis & $25(11.8)$ & $5(9.3)$ & $20(12.7)$ & 0.495 \\
\hline Mechanical thrombectomy & $8(3.8)$ & $3(5.6)$ & $5(3.2)$ & 0.431 \\
\hline IV thrombolysis and/or Mechanical thrombectomy & $30(14.2)$ & $6(11.1)$ & $24(15.3)$ & 0.449 \\
\hline NIHSS at admission, mean $( \pm S D)$ & $7.7(4.7)$ & $10.4(4.5)$ & $6.8(4.5)$ & $<0.001$ \\
\hline NIHSS $<6$ & $98(46.4)$ & $13(24.1)$ & $85(54.1)$ & $<0.001$ \\
\hline NIHSS $\geq 6$ & $113(53.6)$ & $41(75.9)$ & $72(45.9)$ & \\
\hline Lesion volumes at admission, $\mathrm{mL}$ mean $( \pm \mathrm{SD})$ & $15.3(13.5)$ & $18.7(14.9)$ & I4.I (12.8) & 0.031 \\
\hline Hospital stay, days mean $( \pm S D)$ & $13.5(5.7)$ & $14.4(6.0)$ & $13.2(5.6)$ & 0.096 \\
\hline Hospital costs, Yuan mean ( $\pm S D)$ & $12,553(2422)$ & I3,764 (3743) & $12,675(2419)$ & 0.535 \\
\hline \multicolumn{5}{|l|}{ Serum levels of biomarkers at admission, mean $( \pm S D)$} \\
\hline Leptin, ng/mL & $16.8(6.9)$ & $8.9(1.9)$ & $19.5(5.8)$ & $<0.001$ \\
\hline $\mathrm{FSG}, \mathrm{mmol} / \mathrm{l}$ & $6.63(1.94)$ & $6.82(2.37)$ & $6.02(1.77)$ & 0.233 \\
\hline CRP, mg/l & $4.5(2.1)$ & $6.6(3.1)$ & $4.1(2.0)$ & 0.002 \\
\hline Rankin at 3-month median (IQR) & I $(0-3)$ & $4(3-5)$ & I (0-2) & \\
\hline mRS 0-2 & $133(63.0)$ & $13(24.1)$ & $120(76.4)$ & $<0.001$ \\
\hline mRS 3-6 & $78(37.0)$ & $4 \mid(75.9)$ & $37(23.6)$ & - \\
\hline Mortality at 3-month & & & & $<0.001$ \\
\hline Survivors & $179(84.8)$ & $35(64.8)$ & | 44 (9|.7) & - \\
\hline Nonsurvivors & $32(15.2)$ & $19(35.2)$ & $13(8.3)$ & - \\
\hline
\end{tabular}

Notes: ${ }^{\ddagger}$ Results are expressed as number (\%) or as mean (SD). Results between different groups were compared by the chi-square and unpaired T-test when appropriate. Low serum leptin level was defined as the lowest quartile (QI) <1I.6ng/mL. †Sulfonylurea or insulin or, if more than $120 \%$ of ideal body weight, metformin.

Abbreviations: BMI, body mass index; SD, standard deviation; CVD, cardiovascular diseases; TIA, transient ischemic attack; IV, intravenous; NIHSS, the NIH Stoke Scale; FSG, fasting serum glucose; CRP, C reaction proteins; mRS, modified Rankin scale. 
A

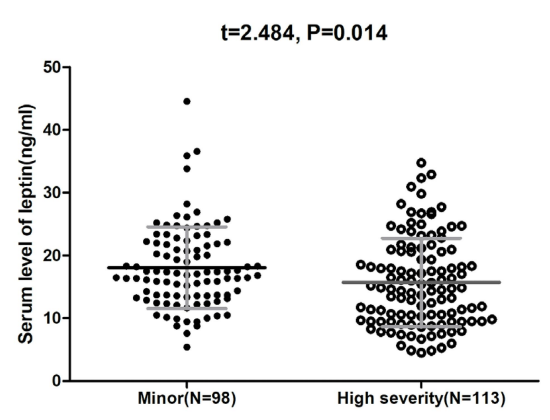

B

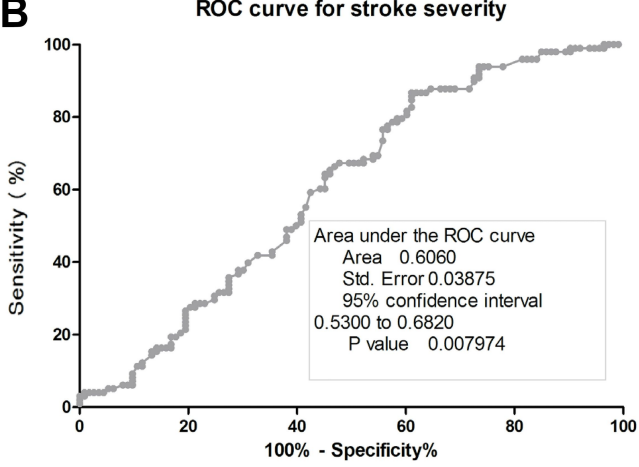

Figure 2 The association between serum leptin and stroke severity at admission. (A) Serum level of leptin in patients with minor stroke and severe stroke. The data presented as mean \pm SD. (B) Receiver operating characteristic (ROC) curve was utilized to evaluate the accuracy of the serum level of leptin to diagnose severe stroke.

$(<11.6 \mathrm{ng} / \mathrm{mL})$ on admission developed poor outcomes, while 37 out of 157 patients $(23.6 \%)$ with normal serum leptin $(<11.6 \mathrm{ng} / \mathrm{mL})$ on admission developed poor outcomes. In a multivariate analysis model, serum leptin levels $<11.6 \mathrm{ng} / \mathrm{mL}$ (lowest quartile, Q1) related to a higher risk of poor functional outcome $(\mathrm{OR}=5.13 ; 95 \%$ $\mathrm{CI}=3.25-6.86 ; \mathrm{P}<0.001$ ) (Table 2). Furthermore, the association between poor outcome and leptin was more pronounced among men (OR [95\% CI]: 5.65[3.77-7.32]) when compared with women (4.95[3.01-6.63]). As shown in Figure 3B, the cut-off value of serum leptin in diagnosing poor functional impairment was estimated to be $13.3 \mathrm{ng} / \mathrm{mL}$ with the AUC (95\% CI) of $0.81(0.74-$ 0.87 ), which suggested that the sensitivity and specificity were $74.0 \%$ and $80.0 \%$, respectively.

At 3 -month, the mortality rate was $15.2 \%(\mathrm{~N}=32)$. The mean leptin serum level in those patients was lower than in those survivors (10.8[SD. 4.4]ng/mL vs $17.8[6.7] \mathrm{ng} / \mathrm{mL}$, $\mathrm{P}<0.001$ ) (Figure 4A). The data showed that 19 out of 54 patients $(35.2 \%)$ with low serum leptin $(<11.6 \mathrm{ng} / \mathrm{mL})$ on admission were nonsurvivors, while 13 out of 157 patients
$(8.3 \%)$ with normal serum leptin $(<11.6 \mathrm{ng} / \mathrm{mL})$ on admission were nonsurvivors. In a multivariate analysis model, serum leptin levels $<11.6 \mathrm{ng} / \mathrm{mL}$ (lowest quartile, Q1) related to a higher risk of mortality $(\mathrm{OR}=3.19 ; 95 \% \mathrm{CI}=2.03-4.25$; $\mathrm{P}<0.001$ ) (Table 2). As shown in Figure 4B, the cut-off value of serum leptin in diagnosing mortality was estimated to be $13.0 \mathrm{ng} / \mathrm{mL}$ with the AUC (95\% CI) of 0.82 (0.74-0.89), which suggested that the sensitivity and specificity were $73.5 \%$ and $79.3 \%$, respectively.

\section{Discussion}

To our knowledge, we firstly assessed the prognostic value of leptin serum levels in ischemic stroke patients with diabetes. The data shows that leptin serum level is a useful prognostic biomarker in ischemic stroke patients with type 2 diabetes, and this relationship is negative, suggesting a neuroprotective role in stroke patients.

As an adipocyte-secreted hormone, leptin affects neuroendocrine function, ${ }^{24}$ and the neuroprotective role against ischemic neuronal injury has been proposed. ${ }^{25}$ The neuroprotection role of leptin during cerebral
A

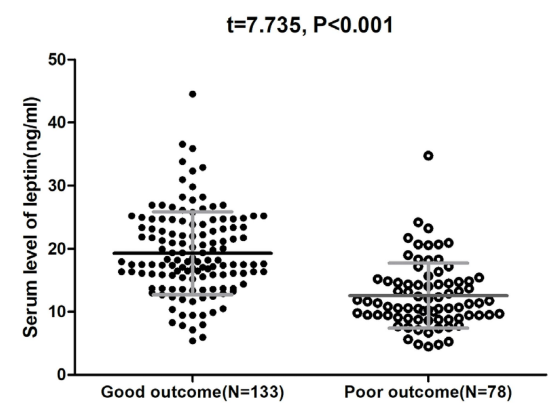

B ROC curve for stroke outcome

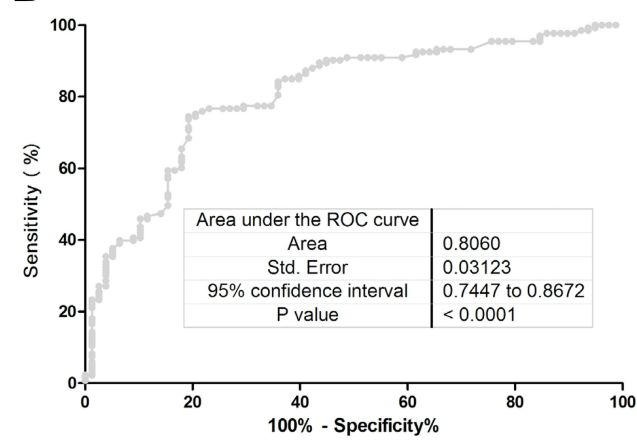

Figure 3 The association between serum leptin and stroke outcome at 3-month. (A) Serum level of leptin in patients with poor functional outcome and good functional outcome. The data presented as a mean \pm SD. (B) Receiver operating characteristic (ROC) curve was utilized to evaluate the accuracy of leptin's serum level to poor functional outcomes. A modified Rankin scale (mRS) score of 3 to 6 points was defined as a poor functional outcome. 
Table 2 Multivariate Analysis of Predictors of Poor Functional Outcome and Mortality ${ }^{\dagger}$

\begin{tabular}{|c|c|c|c|}
\hline & OR & $95 \% \mathrm{Cl}$ & $\mathbf{P}$ \\
\hline \multicolumn{4}{|l|}{ Functiona2l outcome } \\
\hline Leptin $<11.6 \mathrm{ng} / \mathrm{mL}^{\ddagger}$ & 5.13 & $3.25-6.86$ & $<0.001$ \\
\hline NIHSS $>5$ & 7.15 & $4.09-10.23$ & $<0.001$ \\
\hline Acute treatment & 0.36 & $0.30-0.42$ & $<0.001$ \\
\hline CRP (per unit increase) & 1.21 & I.12-1.35 & 0.006 \\
\hline Lesion volumes (per unit increase) & 1.15 & $1.05-1.27$ & 0.013 \\
\hline Duration of diabetes & 2.03 & $1.35-2.69$ & 0.019 \\
\hline \multicolumn{4}{|l|}{ Mortality } \\
\hline Leptin $<11.6 \mathrm{ng} / \mathrm{mL}^{\ddagger}$ & 3.19 & $2.03-4.25$ & $<0.001$ \\
\hline NIHSS $>5$ & 8.29 & $3.65-12.44$ & $<0.001$ \\
\hline Acute treatment & 0.27 & $0.21-0.34$ & $<0.001$ \\
\hline CRP (per unit increase) & 1.28 & $1.10-1.40$ & 0.005 \\
\hline Lesion volumes (per unit increase) & 1.17 & $1.03-1.30$ & 0.011 \\
\hline
\end{tabular}

Notes: ${ }^{\dagger}$ Adjusted for age, gender, BMI, duration of diabetes, diabetes treatment, medication before stroke (hypertension, hypercholesterolemia, atrial fibrillation, cardiovascular diseases, peripheral vascular disease, and transient ischemic attack), NIHSS at admission, stroke subtype, and acute stroke treatment. ‡Serum levels of leptin were categorized into quartiles, and the lowest quartiles $(\mathrm{Q} I=\mid 1.6 \mathrm{ng} / \mathrm{mL})$ were compared to the other three quartiles (as the reference).

ischemia had been suggested by one study, ${ }^{25}$ while another study showed that exogenous leptin administration could protect against ischemic neuronal injury. ${ }^{26}$ Furthermore, Zhang et $\mathrm{al}^{27}$ demonstrated that leptin's neuroprotective role might be related to the increase of Calcitonin generelated peptide expression, while another study suggested that leptin-induced neuroprotection mainly through the PI3K/Akt pathway. ${ }^{28}$ In addition, Zhang et $\mathrm{al}^{29}$ reported that leptin could protect hippocampal CA1 neurons against ischemic injury through ERK1/2 MAPK signaling pathways. At the same time, another suggested that leptin might be used to attenuate ischemic injury after stroke via the induction of an anti-apoptotic state. ${ }^{30}$

\section{A}

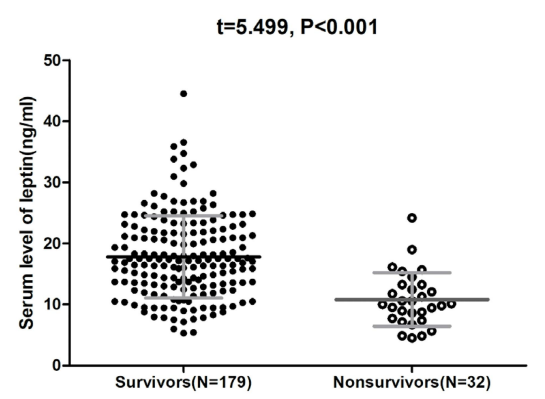

One study also suggested that leptin's benefit after stroke was related to its new neuroprotective role. ${ }^{31}$ Furthermore, the role of leptin in glycaemic control had been suggested, ${ }^{32}$ and the prognostic value of glucose serum level on admission in stroke patients treated with thrombolysis had been proposed. ${ }^{33}$ Also, low adiponectin/ leptin could lead to increased inflammation response and oxidative stress. $^{34}$

As an observational study, we could not obtain a causal relationship between leptin and stroke prognosis. Whether stroke patients with low serum leptin levels need to supplement leptin to maintain optimal concentrations to improve stroke prognosis requires further human trials. Interestingly, one study showed that a combined application of leptin and tissue plasminogen activator could improve stroke prognosis. ${ }^{35}$ However, Avraham et $\mathrm{al}^{31}$ found that leptin-induced neurogenesis and angiogenesis could not contribute to the functional outcome improvement, ${ }^{31}$ while another study reported that elevated leptin plasma level was related to larger infarct volume following tissue plasminogen activator treatment. ${ }^{36}$ Therefore, the therapeutic role of leptin in stroke patients needs further research to verify.

Consistent with our findings, $\mathrm{Ku}$ et $\mathrm{al}^{37}$ showed that low leptin level was related to a high risk of cardiovascular events and mortality in stable coronary artery disease patients. At the same time, another study illuminated that higher leptin/adiponectin at day one was associated with better functional outcomes in atherothrombotic stroke patients. ${ }^{38}$ Furthermore, another study reported that higher baseline leptin level was a protective factor of cardiovascular events (including strokes). ${ }^{39}$ However, conflicting results exist with a study reporting high plasma leptin levels to predict

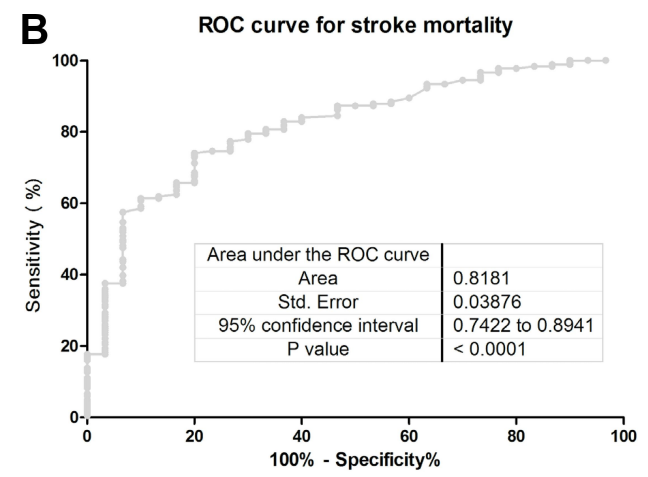

Figure 4 The association between serum leptin and stroke mortality at 3-month. (A) Serum level of leptin in survivors and nonsurvivors. The data presented as mean \pm SD. (B) Receiver operating characteristic (ROC) curve was utilized to evaluate the accuracy of the serum level of leptin to mortality. 
major adverse cardiac events in coronary artery disease patients independently of established risk factors. ${ }^{40}$ Liu et $\mathrm{al}^{15}$ also showed that increasing levels of serum leptin correlated with stroke severity and lesion size. This discrepancy might be caused by the differences in the research population and testing methods. Furthermore, another study found that plasma leptin was an independent predictor of recurrent cardiovascular events in men with earlier acute coronary syndromes. ${ }^{41}$ Similarly, one study showed that leptin was an independent positive predictor of future cardiovascular events in patients with angiographically confirmed coronary atherosclerosis, ${ }^{42}$ and Wallander et $\mathrm{al}^{43}$ showed that high serum levels of leptin were associated with a poorer long-term prognosis in patients with myocardial infarction and without type 2 diabetes mellitus. Another study did not find any significant association between serum leptin levels and the risk of cardiovascular diseases or all-cause mortality in women with diabetes. ${ }^{44}$

Leptin is an adipokine have effects on the cardiovascular system with both protective and harmful role. The above studies assessing the relationship between leptin and prognosis had yielded conflicting results, which might be explained by the obesity paradox.

\section{Clinical Respective}

In ischemic stroke patients with diabetes, low leptin serum levels at admission were independently associated with a poor functional prognosis, suggesting that leptin could be used for attenuating ischemic injury and improving prognosis after stroke.

\section{Study Limitation}

This study included limitations. First, this was a single-center observational study with small samples $(\mathrm{N}=211)$. Besides, it impossible to determine causality associations from this study. Second, we only collected serum samples. The levels of cerebrospinal fluid leptin were not tested. One study showed that leptin could cross the blood-brain barrier and was also synthesized in the brain. ${ }^{35}$ Third, other adipokine biomarkers were not tested. The association of those factors with leptin and stroke prognosis could not be determined.

\section{Conclusions}

The data shows that leptin serum level is a useful prognostic biomarker in ischemic stroke patients with type 2 diabetes, and this relationship is negative. This association is also independent of other factors, including gender and obesity.

\section{Abbreviations}

DWI, Diffusion-weighted imaging; TOAST, Trial of Org 10,172 in Acute Stroke Treatment; NIHSS, National Institutes of Health Stroke Scale; BMI, Body index mass; $\mathrm{CV}$, Coefficient of variation; mRS, modified Rankin scale; SD, Standard deviation; OR, odds ratios; CI, Confidence intervals; ROC, Receiver operating characteristic; AUC, Area under the curve.

\section{Data Sharing Statement}

The data are available from the corresponding author upon reasonable request.

\section{Ethics Approval and Consent to Participate}

The Ethics Committee of Third Affiliated Hospital of Nanchang University approved the trial protocol according to the Declaration of Helsinki (1964). Written Informed consent was obtained from patients before entering the study. We confirmed that any data intended for sharing would be de-identified.

\section{Acknowledgments}

We are grateful to all patients who participated in our study. We also thank Edanz Editing China (www.liwenbianji.cn/ac) for editing the English text of a draft of this manuscript.

\section{Funding}

There is no funding to report.

\section{Disclosure}

The authors report no conflicts of interest for this work.

\section{References}

1. Auwerx J, Staels B. Leptin. Lancet. 1998;351(9104):737-742. doi:10.1016/S0140-6736(97)06348-4

2. Ahima RS, Flier JS. Leptin. Annu Rev Physiol. 2000;62(1):413-437. doi:10.1146/annurev.physiol.62.1.413

3. Loffreda S, Yang SQ, Lin HZ, et al. Leptin regulates proinflammatory immune responses. FASEB J. 1998;12(1):57-65. doi:10.1096/ fsb2fasebj.12.1.57

4. McNeely MJ, Boyko EJ, Weigle DS, et al. Association between baseline plasma leptin levels and subsequent development of diabetes in Japanese Americans. Diabetes Care. 1999;22(1):65-70.

5. Ghadge AA, Khaire AA. Leptin as a predictive marker for metabolic syndrome. Cytokine. 2019;121:154735.

6. Ghantous CM, Azrak Z, Hanache S, Abou-Kheir W, Zeidan A. Differential role of leptin and adiponectin in cardiovascular system. Int J Endocrinol. 2015;2015:1-13. doi:10.1155/2015/534320

7. Beltowski J. Leptin and atherosclerosis. Atherosclerosis. 2006;189 (1):47-60. doi:10.1016/j.atherosclerosis.2006.03.003 
8. Knudson JD, Dincer UD, Zhang C, et al. Leptin receptors are expressed in coronary arteries, and hyperleptinemia causes significant coronary endothelial dysfunction. Am J Physiol Heart Circ Physiol. 2005;289(1):H48-H56.

9. Coppari R, Bjørbæk C. Leptin revisited: its mechanism of action and potential for treating diabetes. Nat Rev Drug Discov. 2012;11 (9):692-708.

10. Reilly MP, Iqbal N, Schutta M, et al. Plasma leptin levels are associated with coronary atherosclerosis in type 2 diabetes. $J$ Clin Endocrinol Metab. 2004;89(8):3872-3878. doi:10.1210/jc.2003031676

11. Katsiki N, Mikhailidis DP, Banach M. Leptin, cardiovascular diseases and type 2 diabetes mellitus. Acta Pharmacol Sin. 2018;39 (7):1176-1188.

12. Söderberg S, Stegmayr B, Stenlund H, et al. Leptin, but not adiponectin, predicts stroke in males. J Intern Med. 2004;256(2):128-136. doi:10.1111/j.1365-2796.2004.01351.x

13. Yang $\mathrm{H}$, Guo W, Li J, et al. Leptin concentration and risk of coronary heart disease and stroke: a systematic review and meta-analysis. PLoS One. 2017;12(3):e0166360. doi:10.1371/journal.pone. 0166360

14. Bidulescu A, Liu J, Chen Z, et al. Associations of adiponectin and leptin with incident coronary heart disease and ischemic stroke in African Americans: the Jackson heart study. Front Public Health. 2013;1:16. doi:10.3389/fpubh.2013.00016

15. Liu G, Dong M, Ma S, et al. Serum leptin is associated with first-ever ischemic stroke, lesion size and stroke severity in a Chinese cohort. Neurol Res. 2019;41(2):125-131. doi:10.1080/01616412.20 18.1544399

16. Jimenez I, Sobrino T, Rodriguez-Yanez M, et al. High serum levels of leptin are associated with post-stroke depression. Psychol Med. 2009;39(7):1201. doi:10.1017/S0033291709005637

17. Gairolla J, Kler R, Modi M, Khurana D. Leptin and adiponectin: pathophysiological role and possible therapeutic target of inflammation in ischemic stroke. Rev Neurosci. 2017;28(3):295-306.

18. Hatano S. Experience from a multicentre stroke register: a preliminary report. Bull World Health Organ. 1976;54:541-553.

19. Yang W, Lu J, Weng J, et al. Prevalence of diabetes among men and women in China. $N$ Engl J Med. 2010;362(12):1090-1101. doi:10.1056/NEJMoa0908292

20. Sims JR, Gharai LR, Schaefer $\mathrm{PW}$, et al. $\mathrm{ABC} / 2$ for rapid clinical estimate of infarct, perfusion, and mismatch volumes. Neurology. 2009;72(24):2104-2110. doi:10.1212/WNL.0b013e3181aa5329

21. Adams HP, Bendixen BH, Kappelle LJ, et al. Classification of subtype of acute ischemic stroke. Definitions for use in a multicenter clinical trial. TOAST. Trial of Org 10172 in acute stroke treatment. Stroke. 1993;24(1):35-41. doi:10.1161/01.STR.24.1.35

22. Huang GQ, Cheng HR, Wu YM, et al. Reduced vitamin D levels are associated with stroke-associated pneumonia in patients with acute ischemic stroke. Clin Interv Aging. 2019;14:2305-2314. doi:10.2147/ CIA.S230255

23. Tu WJ, Dong X, Zhao SJ, Yang DG, Chen H. Prognostic value of plasma neuroendocrine biomarkers in patients with acute ischaemic stroke. J Neuroendocrinol. 2013;25(9):771-778. doi:10.1111/ jne. 12052

24. Park HK, Ahima RS. Physiology of leptin: energy homeostasis, neuroendocrine function and metabolism. Metabolism. 2015;64 (1):24-34.

25. Zhang F, Wang S, Signore AP, Chen J. Neuroprotective effects of leptin against ischemic injury induced by oxygen-glucose deprivation and transient cerebral ischemia. Stroke. 2007;38(8):2329-2336. doi:10.1161/STROKEAHA.107.482786

26. Valerio A, Dossena M, Bertolotti P, et al. Leptin is induced in the ischemic cerebral cortex and exerts neuroprotection through NF- $\mathrm{kB} /$ c-Rel-dependent transcription. Stroke. 2009;40(2):610-617. doi:10.1161/STROKEAHA.108.528588
27. Zhang JY, Yan GT, Liao J, et al. Leptin attenuates cerebral ischemia/ reperfusion injury partially by CGRP expression. Eur J Pharmacol. 2011;671(1-3):61-69. doi:10.1016/j.ejphar.2011.09.170

28. Zhang J, Deng Z, Liao J, et al. Leptin attenuates cerebral ischemia injury through the promotion of energy metabolism via the PI3K/Akt pathway. J Cereb Blood Flow Metab. 2013;33(4):567-574. doi:10.1038/jcbfm.2012.202

29. Zhang F, Chen J. Leptin protects hippocampal CA1 neurons against ischemic injury. $J$ Neurochem. 2008;107(2):578-587. doi:10.1111/ j.1471-4159.2008.05645.x

30. Avraham Y, Davidi N, Porat M, et al. Leptin reduces infarct size in association with enhanced expression of CB2, TRPV1, SIRT-1 and leptin receptor. Curr Neurovasc Res. 2010;7(2):136-143. doi: $10.2174 / 156720210791184943$

31. Avraham Y, Dayan M, Lassri V, et al. Delayed leptin administration after stroke induces neurogenesis and angiogenesis. $J$ Neurosci Res. 2013;91(2):187-195. doi:10.1002/jnr.23147

32. Meek TH, Morton GJ. The role of leptin in diabetes: metabolic effects. Diabetologia. 2016;59(5):928-932.

33. Desilles JP, Meseguer E, Labreuche J, et al. Diabetes mellitus, admission glucose, and outcomes after stroke thrombolysis: a registry and systematic review. Stroke. 2013;44(7):1915-1923. doi:10.1161/ STROKEAHA.111.000813

34. Frühbeck G, Catalán V, Rodríguez A, et al. Involvement of the leptin-adiponectin axis in inflammation and oxidative stress in the metabolic syndrome. Sci Rep. 2017;7(1):1-8. doi:10.1038/s41598017-06997-0

35. Signore AP, Zhang F, Weng Z, Gao Y, Chen J. Leptin neuroprotection in the CNS: mechanisms and therapeutic potentials. $J$ Neurochem. 2008;106(5):1977-1990. doi:10.1111/j.1471-4159.2008.05457.x

36. Calleja AI, Cortijo E, García-Bermejo P, et al. Blood biomarkers of insulin resistance in acute stroke patients treated with intravenous thrombolysis: temporal profile and prognostic value. Diabetes Res Clin Metab. 2013;2(1):2. doi:10.7243/2050-0866-2-2

37. Ku IA, Farzaneh-Far R, Vittinghoff E, Zhang MH, Na B, Whooley MA. Association of low leptin with cardiovascular events and mortality in patients with stable coronary artery disease: the heart and soul study. Atherosclerosis. 2011;217(2):503-508. doi:10.1016/j. atherosclerosis.2010.10.047

38. Carbone F, Burger F, Roversi G, et al. Leptin/adiponectin ratio predicts poststroke neurological outcome. Eur J Clin Invest. 2015;45 (11):1184-1191. doi:10.1111/eci.12538

39. Wolk R, Bertolet M, Singh P, et al. Prognostic value of adipokines in predicting cardiovascular outcome: explaining the obesity paradox. Mayo Clin Proc. 2016;91(7):858-866. doi:10.1016/j.mayocp.2016.03.020

40. Puurunen VP, Kiviniemi A, Lepojärvi S, et al. Leptin predicts short-term major adverse cardiac events in patients with coronary artery disease. Ann Med. 2017;49(5):448-454. doi:10.1080/ 07853890.2017.1301678

41. Söderberg S, Colquhoun D, Keech A, et al. Leptin, but not adiponectin, is a predictor of recurrent cardiovascular events in men: results from the LIPID study. Int $J$ Obes. 2009;33(1):123-130. doi:10.1038/ijo.2008.224

42. Wolk R, Berger P, Lennon RJ, Brilakis ES, Johnson BD, Somers VK. Plasma leptin and prognosis in patients with established coronary atherosclerosis. $J$ Am Coll Cardiol. 2004;44(9):1819-1824. doi:10.1016/j.jacc.2004.07.050

43. Wallander M, Söderberg S, Norhammar A. Leptin - a predictor of abnormal glucose tolerance and prognosis in patients with myocardial infarction and without previously known type 2 diabetes. Diabet Med. 2008;25(8):949-955. doi:10.1111/j.1464-5491.2008.02509.x

44. Brennan AM, Li TY, Kelesidis I, Gavrila A, Hu FB, Mantzoros CS. Circulating leptin levels are not associated with cardiovascular morbidity and mortality in women with diabetes: a prospective cohort study. Diabetologia. 2007;50(6):1178-1185. doi:10.1007/s00125007-0635-y 


\section{Publish your work in this journal}

Clinical Interventions in Aging is an international, peer-reviewed journal focusing on evidence-based reports on the value or lack thereof of treatments intended to prevent or delay the onset of maladaptive correlates of aging in human beings. This journal is indexed on PubMed Central, MedLine, CAS, Scopus and the Elsevier
Bibliographic databases. The manuscript management system is completely online and includes a very quick and fair peer-review system, which is all easy to use. Visit http://www.dovepress.com/ testimonials.php to read real quotes from published authors.

Submit your manuscript here: https://www.dovepress.com/clinical-interventions-in-aging-journal 